\title{
The Effect of Unsaturated Fatty Acids on Molecular Markers of Cholesterol Homeostasis in THP-1 Macrophages
}

\author{
Javad Zavar Reza ${ }^{1}$, Hossein Nahangi ${ }^{2}$, Reza Mansouri ${ }^{3}$, Ali Dehghani ${ }^{4}$, Majid Mojarrad ${ }^{5}$, \\ Mohammad Fathi ${ }^{6,}$, Abdolrahim Nikzamir $^{7}$, Mir Saeed Yekaninejad ${ }^{8}$ \\ ${ }_{1}^{1}$ Department of Biochemistry, Faculty of Medicine, Shahid Sadoughi University of Medical Sciences, Yazd, IR Iran \\ 2 Department of Anatomy, Faculty of Medicine, Shahid Sadoughi University of Medical, Yazd, IR Iran \\ 3 Department of Immunology, Faculty of Medicine, Shahid Sadoughi University of Medical Sciences, Yazd, IR Iran \\ 4 Department of Biostatistics and Epidemiology, Faculty of Health, Shahid Sadoughi University of Medical Sciences, Yazd, IR Iran \\ 5 Department of Medical Genetics, School of Medicine, Mashhad University of Medical Sciences, Mashhad, IR Iran \\ 6 Department of Medical Genetics, School of Medicine, Mashhad University of Medical Sciences, Mashhad, IR Iran \\ ${ }_{7}$ Endocrine Research Center, Valiasr Hospital, Tehran University of Medical Sciences, Tehran, IR Iran \\ 8 Endocrine Research Center, Valiasr Hospital, Tehran University of Medical Sciences, Tehran, IR Iran \\ ${ }^{*}$ Corresponding author: Mohammad Fathi, Department of Anesthesiology, Faculty of Medicine, Mofid Children's Hospital, Shahid Beheshti University of Medical Sciences, Tehran, IR \\ Iran. Tel:+98-2181453074, Fax:+98-2181453074, E-mail: Fathi_mansor@yahoo.com.
}

Received: April 25, 2013; Revised: May 20, 2013; Accepted: May 25, 2013

Background: Macrophages derived foam cells are key factors in the maladaptive immune and inflammatory response.

Objectives: The study of the cholesterol homeostasis and the molecular factor involved in these cells is very important in understanding the process of atherosclerosis and the mechanisms that prevent its occurrence.

Materials and Methods: This experimental study investigated the effects of c9, t11-Conjugated Linoleic Acid (c9, t11-CLA). Alpha Linolenic Acid (LA), and Eicosapentaenoic Acid (EPA) on the PPAR $\alpha$ and ACAT1 mRNA expression by Real time PCR and cholesterol homeostasis in THP-1 macrophages derived foam cells.

Results: Incubation of CLA, LA, EPA, and synthetic ligands did not prevent increasing the cellular total cholesterol (TC). Free cholesterol (FC) is increased by Sandoz58-035 $(\mathrm{P}=0.024)$ and decreased by fatty acids and Wy14643 (Pirinixic acid $)(\mathrm{P}=0.035)$. The pattern of distribution of \% $\mathrm{EC}$ is similar to the EC pattern distribution. The ACAT1 mRNA expression was significantly increased by EPA $(\mathrm{P}=0.009)$, but c9, t11- CLA, LA, Wy14643, and Sandoz58-035 had no significant effect on the mRNA level of ACAT1 expression compared to DMSO(Dimethyl sulfoxide). Discussions: In comparison to the control of Wy14643, Sandoz58-035, c9 and t11-CLA, EPA increased the PPAR $\alpha$ mRA levels $(\mathrm{P}=0.024, \mathrm{P}=$ $0.041, \mathrm{P}=0.043$, and $\mathrm{P}=0.004$, respectively), even though, LA had no significant effect on the PPAR $\alpha$ mRA expression $(\mathrm{P}=0.489)$.

Conclusions: Variations in the chemical structure of fatty acids can affect their physiological function.

Keywords: Atherosclerosis; Macrophages; Receptors, Oxidized LDL; Peroxisome Proliferator-Activated Receptors

\section{Background}

Atherosclerosis is one of the main causes of death in advanced countries (1). Atherosclerosis initiates with the accumulation of apolipoprotein B-containing lipoproteins in the subendothelial of the artery (2). The blood flow carries these Lipoproteins to the intima layer and subsequently with their oxidative modification; an early inflammatory response is raised. The activation of endothelial cells leads to the recruitment of blood-borne monocytes and immigration of them to the subendothelial layer $(3,4)$. By the macrophage colony-stimulating factor (M-CSF) and other differentiation factors, the monocytes were differentiated to macrophage in early atherosclerotic lesions $(5,6)$. In the beginning of formation and progress of atherogenesis, many macrophages have many lipid droplets in the cytoplasm. The formation of these lipid-loaded macrophages or foam cells begins when they uptake and process modified Low Density Lipoproteins (m-LDL), especially oxidized LDL (ox-LDL) via scavenger receptors (7). After digestion, the cholesterol esters (CE) of the LDLs are hydrolyzed to free cholesterol and fatty acids (8). The free cholesterol can leave the cell or undergo re-esterification to CE by the ER enzyme acylCoA: cholesterol ester transfers (ACAT) (9). Therefore, the accumulation of cholesterol ester droplets in cells like as MQs occurs. Some studies have shown that the upregulation of the ACAT1 expression in monocytes and MQs is strongly associated with the initiation and progression of the atherosclerosis in cell culture and in experimental

Implication for health policy/practice/research/medical education:

The purpose of the present study was to elucidate the ability of ofw-fatty acids and conjugated fatty acids in the prevention of foam cell formation through the effect on the gene expression of PPARI \pm and ACAT1.

Copyright (C) 2013, Iranian Red Crescent Medical Journal; Licensee Kowsar Ltd. This is an Open Access article distributed under the terms of the Creative Commons Attribution License (http://creativecommons.org/licenses/by/3.0), which permits unrestricted use, distribution, and reproduction in any medium, provided the original work is properly cited. 
animal models (9-12). Fatty acids are important ligands for LXR (liver X receptor) (13) and PPAR $(14,15)$.These transcriptions are as a substrate for ACAT1, so different fatty acids can have different effects on these factors and influence cholesterol homeostasis in macrophage (16). The ACAT1 mRNA levels increased in macrophages compared to monocytes of the mouse liver in response to a high fat, and high cholesterol diet (17-19). Also some studies have shown that free fatty acids can regulate the ACAT1 gene expression $(14,17,18)$.

\section{Objectives}

This experimental study was designed to elucidate the ability of w-fatty acids and conjugated fatty acids in the prevention of foam cell formation through the effect on the gene expression of PPAR $\alpha$ and ACAT1.In this study, The ACAT1 mRNA expression was significantly increased by EPA, but c9, t11- CLA, LA, Wy14643, and Sandoz58-035 had no significant effect on the mRNA level of ACAT1 expression compared to DMSO.

\section{Materials and Methods}

\subsection{Materials}

The THP-1 cell was obtained from the IR Iranian branch of Institute Pasture. Cell culture media, Glutamine, penicillin, and streptomycin media supplement, the Serum Free Medium (SFM) and the fetal bovine serum (FBS) were obtained from the Invitrogen Corporation, Paisley, UK. Phorbol 12-myristate13-acetate (PMA), dimethyl sulfoxide (DMSO), Wy 14643, Sandoz 58-035, the linolenic acid, the eicosapentaenoic acid, and the conjugated linoleic acid were obtained from Sigma-Aldrich, The USA. Ac-LDL was purchased from calbiochem com, The USA. Reagents, kits for RNA extraction, reverse transcription and SYBER Green, and PCR Master Mix Reagents were obtained from Qiagen, The USA. All other chemicals were obtained from Sigma Aldrich, The USA. Human monocytic THP-1 cells were cultured in the RPMI 1640 medium, supplemented with a $10 \%$ fetal bovine serum (FBS), streptomycin, amphotericin $\mathrm{B}$, sodium pyruvate, $2 \mathrm{mM}$ L glutamine, 50 $\mu \mathrm{M}$ of 2 -mercaptoethanol in a humid atmosphere containing $5 \% \mathrm{CO} 2$ at $37^{\circ} \mathrm{C}$. For experimental purposes, cells were cultured at a $1 \times 106$ density in a serum free media (SFM). All tests were performed in triplicate. Two expert researchers performed the tests. The inter-rater reliability between two evaluators was 0.91 .

\subsection{Cell Differentiation and Fatty Acid Treatment}

For differentiation of THP- 1 to macrophage, THP- 1 cells were washed with serum free RPMI 1640 and resuspended in SFM in the presence of $100 \mathrm{ng} / \mathrm{ml}$ phorbol 12-myristate 13-acetate (PMA) for $72 \mathrm{~h}$ (19). All fatty acids and synthetic ligands were dissolved in DMSO (the final concentration was $\leq 0.1 \%$ ). Cells were pretreated with fatty acids and chemical ligands before cholesterol loading for $24 \mathrm{~h}$, and then for the induction of foam cell transformation, cells were incubated with a $50 \mu \mathrm{g} / \mathrm{ml}$ Ac-LDL in the SFM medium for $48 \mathrm{~h}$ (20). The concentration of fatty acids and chemical ligands in this experiment were: $100 \mu \mathrm{M}$ for LA, EPA and CLA, $50 \mu \mathrm{M}, 5 \mu \mathrm{M}$ for Wy14643Sandoz 58- 035, respectively.

3.3. RNA Extraction and Real Time Quantitative RT-PCR Analysis

The mRNA levels were quantitated by a real-time PCR. Instruments were calibrated before conducting the trial and the inter rater reliability of two evaluators were calculated by ICC (Intra class correlation). The ICC of inter rater reliability for PCR and ELISA were 0.89 and 0.92 respectively. The total RNA was extracted from THP- 1 foam cells using the RNA kit (Qiagen, The USA). RNA was stored at $-70^{\circ} \mathrm{C}$ until real-time polymerase chain reaction (PCR) occurred. RNA for real time PCR, was reversed transcribed according to the manufacturer's protocol using the quantiTect Reverse Transcription Kit (Qiagen, The USA). The Real Time PCR was performed by the SYBER Green PCR Master Mix Reagent. The cycling parameters were $95^{\circ} \mathrm{C}$ for $10 \mathrm{~min}$, then, 40 cycles at $95^{\circ} \mathrm{C}$ for $15 \mathrm{~s}$, and $60^{\circ} \mathrm{C}$ for $60 \mathrm{~s}$. The housekeeping $\beta$-Actin was normalized.

\subsection{Toxicology Assay}

The viability of treated cells was quantified spectrophotometrically by the 2, 3-bis (2-methoxy-4- Nitro5-sulfophenyl)-S-| (phenylamino) carbonyl|-2-tetrazoliumhydroxide (XXT) assay (Sigma- Aldrich) (21) . Results were expressed as a percentage of cell viability with respect to control absorbance (100\% cell viability). The XTT assay showed that the LA, CLA, EPA and synthetic ligands have no effect on the cell viability in THP-1 in comparison with the control group (data not shown).

\subsection{Cellular Cholesterol Measurement}

Cells were washed twice with Phosphate Buffer Saline (PBS) and homogenized in $200 \mu \mathrm{l}$ hexane-isopropanol (3:2) (22). The organic phase was used for the TC and EC measurement by enzymatic assays (Calbiochem, The USA). FC was measured as the difference between TC and EC.

The Bradford assay was used for the measurement of cellular proteins (23), and the results were presented as $\mu \mathrm{g}$ lipids/mg cellular proteins.

\subsection{Statistical Analysis}

All results were presented as Mean \pm SD. Quantitative variables in groups were compared by one-way ANOVA, with Tukey multiple comparison test. The homogeneity of variance assumption for ANOVA was checked. The level of significance for all statistical analyses was set at 0.05 . Analysis was performed using SPSS software. 


\section{Results}

\subsection{Cellular TC, EC, FC and \%EC in Macrophages}

Incubation of fatty acid and synthetic ligands could not prevent increasing in the cellular TC. FC was increased by Sandoz58-035 ( $\mathrm{P}=0.024)$, and decreased by fatty acid and Wy14643 $(\mathrm{P}=0.035)$. Sandoz58-035 could inhibit increasing in the EC concentration $(\mathrm{P}=0.038)$, in comparison with the Sandoz58-035, and control group. The concentration of EC in the fatty acids groups increased significantly $(\mathrm{P}=0.028)$. The distribution pattern of \%EC is similar to the EC pattern. This means that Sandoz58-035 could prevent the increased cellular EC and \%EC but in other groups EC and \%EC significantly increased (Figure 1).

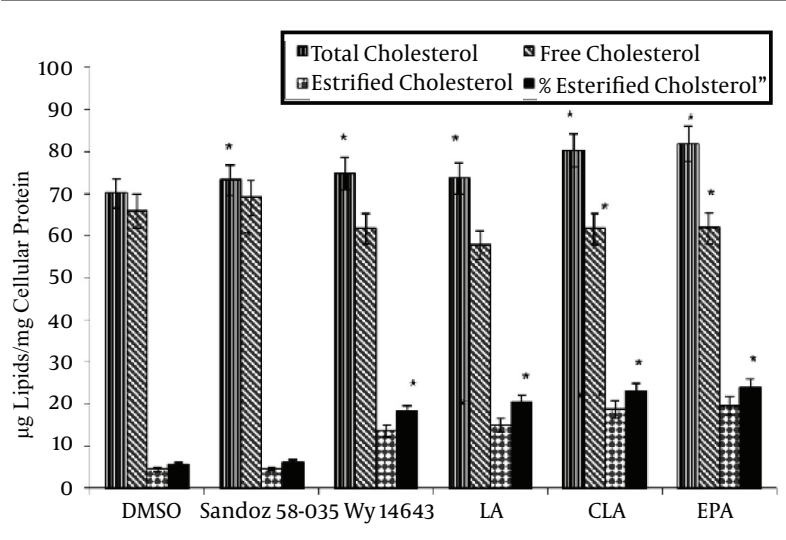

Figure 1. Effects of Fatty Acids on The Intracellular Total Cholesterol (TC), Free Cholesterol (FC) and Esterified Cholesterol (EC) Levels in THP-1 Derived Macrophages and Foam Cells.

THP-1 derived macrophages were cholesterol-loaded with Ac LDL $(50 \mu \mathrm{g} / \mathrm{mL})$ for 48 hours. Wy14643 $(50 \mu \mathrm{mol} / \mathrm{L})$ and Sandoz58-035 $(5 \mu \mathrm{M})$ were added 24 hours before cholesterol- loading. TC and FC were enzymatically determined and $\mathrm{CE}$ was calculated as the difference between TC and FC. Results are the Mean (SD) of triplicate determinations, representative of 3 independent experiments. Statistically significant differences between treatments were indicated by one-way ANOVA followed by the Tukey multicomparison test. Compared to the controls, all treatments were significant at 0.05 level control Wy14643, Sandoz 58-el.

\subsection{Molecular Markers of Macrophage Cholesterol Metabolism}

Figures 2 and 3 show the effects of LA, CLA, and EPA on the PPAR $\alpha$ and ACAT1 mRNA expression, in comparison to WY-14643 (a PPAR $\alpha$ agonist) and Sandoz 58-035 an ACAT1 inhibitor). The ACAT1 mRNA expression was significantly increased by EPA ( $\mathrm{P}=0.009)$. However, $\mathrm{c} 9$, t11- CLA, LA, Wy14643 and Sandoz 58-035 had no significant effect on the mRNA level of ACAT1 expression compared to DMSO (Figure 2).

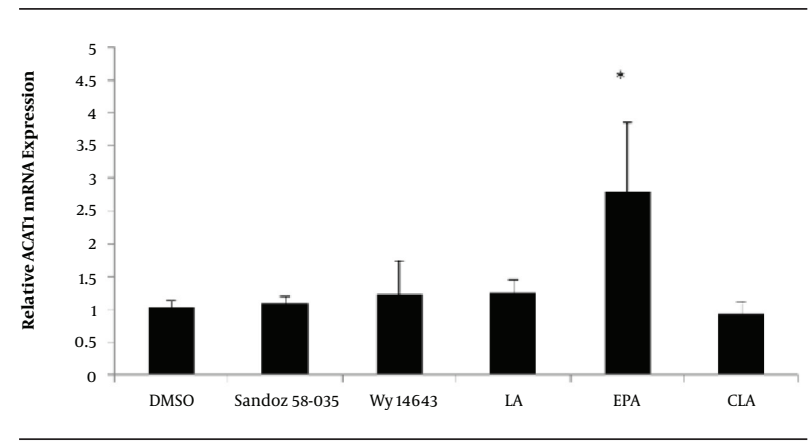

Figure 2. The Effects Of Fatty Acids $(100 \mu \mathrm{M})$, Wy $14643(50 \mu \mathrm{mol} / \mathrm{L})$ and Sandoz58-035 $(5 \mu \mathrm{M})$ on mRNA Levels of ACATI in THP-1 Macrophages Derived Foam Cells.

Cells were treated for $48 \mathrm{~h}$ with fatty acids and pharmacological compounds, and the mRNA levels were analyzed by cyber green procedures. The values were normalized to $\beta$-actin. All results represent means of \pm SD from triplicate determinations, representative of 3 independent experiments compared to control. Significant differences between treatments were indicated by oneway ANOVA followed by the Tukey multicomparison test. In comparison to the control Wy14643, Sandoz 58-035, c9, t11-CLA, and EPA increased PPAR $\alpha$ mRNA levels $(\mathrm{P}=0.024$, $\mathrm{P}=0.041, \mathrm{P}=0.043, \mathrm{P}=0.004$ respectively); although, $\mathrm{LA}$ had no significant effect on the PPAR $\alpha$ mRNA expression $(\mathrm{P}=0.489)$ (Figure 3$)$.

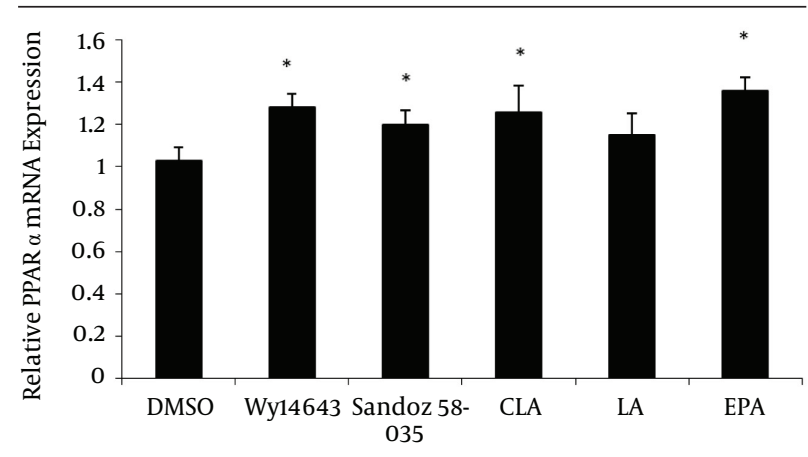

Figure 3. The Effects of Fatty Acids $(100 \mu \mathrm{M})$ and Pharmacological PPAR and ACATI Ligands on mRNA Levels of PPAR $\alpha$ in THP-1 MACROPHAGEs Derived Foam Cells. ${ }^{*} \mathrm{P} \leq 0.05$.

Cells were treated for $48 \mathrm{~h}$ with fatty acids and pharmacological compounds. The mRNA levels were analyzed by cyber green procedures and the values were normalized to $\beta$-actin. All results represent means of \pm SD from triplicate determinations, representative of 3 independent experiments compared to the control. Significant differences between treatments were indicated by one-way ANOVA followed by the Tukey multicomparison test. 


\subsection{Molecular Markers of Macrophages and Foam Cells Cholesterol Metabolism}

The ACAT1 mRNA expression was significantly increased by EPA $(P=0.009)$ but c9, t11- CLA, LA, Wy14643 and Sandoz 58-035 had no significant effect on the mRNA level of ACAT1 expression compared to the control. Compared to control, Wy14643, Sandoz 58-035, c9, t11-CLA and EPA, increase PPAR $\alpha$ mRNA levels $(\mathrm{P}=0.024, \mathrm{P}=0.041, \mathrm{P}=0.043$, $\mathrm{P}=0.004$ respectively); although, LA had no significant effect on the PPAR $\alpha$ mRNA expression $(P=0.489)$ (Figure 3). Also data showed that these fatty acids increase the mRNA level of PPAR $\alpha$ when compared to Sandoz58-035.

\section{Discussion}

Foam cell derived macrophages are key players involved in the initiation and progression of atherosclerosis (24). THP-1 monocyte-macrophages were previously established as a valuable model for studying the lipid homeostasis in human macrophages $(25,26)$ and have been used in this study to evaluate the effects of natural and pharmacological ligands in lipid metabolism of MQs and MQ-derived foam cells. These cells were formed when MQs uptake many modified LDL particles via the scavenger cells $(25,26)$. Many studies have shown that n-3 (27-29) and Conjugated fatty acids (CLA) have roles in prevention of progression and promoting process of atherosclerosis, and thus are useful as potent antiatherogenic nutrients in vivo (30). Although other researchers, like Mondy, et al. showed the role of the proatherogenic potential of CLA in C57BL/6 mice (31). In our previous study, we showed that these fatty acids can reduce the cholesterol content of macrophage derived foam cells (14). In the present study, we investigated the effects of the n-3fatty acids and CLA on the prevention of foam cells formation (cholesterol distribution and some molecular factors) in THP-1 derived macrophage cells. In this study we showed that the incubation of cells with fatty acids, and synthetic ligands could not prevent elevation in the intracellular TC. FC was increased by Sandoz58-035 (an ACAT inhibitor) and decreased by a fatty acid, and Wy14643. Sandoz58-035 inhibited the elevation in intracellular EC concentration. In comparison to Sandoz 50-035, the concentration of EC in fatty acids groups increased significantly. The pattern of distribution of \%EC was similar to the EC pattern. This means that Sandoz58-035 (ACAT1 inhibitor) could prevent the increased intracellular EC and \%EC but in others groups, intracellular EC and \%EC increased. These data were similar to the results obtained by Weldon et al. (19). However McLaren JE et al., showed that EPA and DHA reduce ac-LDL uptake (EPA increased ox-LDL uptake) (32), and this effect is due to the activation of PPAR $\alpha$, and consequently its target genes specially scavenger receptor CD36, and this results in the increased uptake of oxLDL. Chinetti et al. showed that preincubation of MQs with Wy14643 did not modify macrophage AcLDL-induced to- tal cholesterol accumulation. However, they found that cholesterol distribution changes with a significant decrease of the CE fraction (20). The increase in CE is due to an increased expression of the ACAT1 gene, because the ACAT1 mRNA levels increased by fatty acids. However Sandoz 58-035 and Wy14643 did not alter the gene expression of ACAT1, but these compounds have effects on the gene expression or activity of other enzymes such as fatty acid synthase, carnitine palmitoyl transferase 1(CPT-1), CD36, scavenger receptor-A, stearoyl CoA desaturase 1 (33), and scavenger receptor-independent mechanism (32).

These researches indicated that fatty acids such as EPA and DHA are capable of regulating the macrophage foam cell formation (33). Also some studies have suggested that the cell-specific manner gene expression of ACAT1 and effect of fatty acids on the ACAT1 mRNA stability may lead to various levels of ACAT1 mRNA expression in different studies. In the present study, the ACAT1 mRNA expression was significantly increased by EPA, but c9, t11 CLA, LA, Wy14643, and Sandoz 58-035 had no significant effect. PPAR $\alpha$ is another important gene in lipid metabolism in foam cells which we studied in our research (32, 34). PPAR $\alpha, \gamma$, and $\delta$ are expressed in a variety of metabolic tissues and cell types, including epithelial, Endothelial and immune cells, reflecting their pleiotropic functions in fatty acid homeostasis (15). PPAR $\alpha$ is an important lipid-activated transcription factor whose transcriptional target genes have many roles in lipid and glucose metabolism and inflammatory processes (34). Many studies have shown that dietary fatty acids did not significantly change the mRNA level of PPAR $\alpha$ in THP-1 derived macrophages, foam cells, and other tissues $(19,35-37)$. But other studies have indicated opposite results $(38,39)$. Some of studies have shown that different fatty acids could have different effects on the gene expression of PPAR $\alpha$ (14). In macrophages, the transcriptional target of PPAR $\alpha$ (such as CPT-1) regulates the balance between free cholesterol and cholesterol esters (19). So the activation of PPAR $\alpha$ by natural or synthetic ligands can induce the expression of enzymes which reduces the intracellular TC and EC (14, 20, 40).

Our findings showed that Wy14643, Sandoz 58-035, c9, t11-CLA, and EPA increased the PPAR $\alpha$ mRNA levels, but LA had no significant effect on the PPAR $\alpha$ mRNA expression. These effects are different with those observed in our previous study (14). But it is important to understand that the stimulation of cholesterol efflux to the plasma membrane by other factors such as genes regulated by LXR (41), sterol regulatory element binding protein 1(SREBP1) (42) may have an important role in a reduced intracellular cholesterol as a substrate for ACAT1, thus a reduction in the intracellular TC and EC content (43). Macrophages and macrophages derived foam cells are both crucial targets for the regression of atherosclerosis. The results of this study indicate the ability of these fatty acids in the alteration of cholesterol distribution in macrophage and 
foam cell formation. Importantly, the results presented provide significant evidence that macrophages and macrophage derived foam cells are critical cellular targets of CLA, n-3 fatty acids, and thus provide new avenues of investigation which may elucidate their exact mechanism in atherosclerosis process. Also we considered that different fatty acids, such as ligands, have different affinity for transcription factors or enzymes, thus they have different effects on the lipid metabolism in foam cells. At this point, we can explain the different results obtained by various researchers. Also one ligand (for example n-fatty acids) affects the cell metabolism by several mechanisms which can be very complicated (42), and this can be explained by different results obtained by various researchers.

\section{Authors' Contribution}

None declared.

\section{Financial Disclosure}

The author reports no conflicts of interest.

\section{Funding Support}

None declared.

\section{References}

1. Roger VL, Go AS, Lloyd-Jones DM, Benjamin EJ, Berry JD, Borden WB, et al. Executive summary: heart disease and stroke statistics--2012 update: a report from the American Heart Association. Circulation. 2012;125(1):188-97.

2. Mora S, Szklo M, Otvos JD, Greenland P, Psaty BM, Goff DC, Jr, et al. LDL particle subclasses, LDL particle size, and carotid atherosclerosis in the Multi-Ethnic Study of Atherosclerosis (MESA). Atherosclerosis. 2007;192(1):211-7.

3. Mestas J, Ley K. Monocyte-endothelial cell interactions in the development of atherosclerosis. Trends Cardiovasc Med. 2008;18(6):228-32.

4. Moore KJ, Tabas I. Macrophages in the pathogenesis of atherosclerosis. Cell. 2011;145(3):341-55.

5. Johnson JL, Newby AC. Macrophage heterogeneity in atherosclerotic plaques. Curr Opin Lipidol. 2009;20(5):370-8.

6. Paulson KE, Zhu SN, Chen M, Nurmohamed S, Jongstra-Bilen J, Cybulsky MI. Resident intimal dendritic cells accumulate lipid and contribute to the initiation of atherosclerosis. Circ Res. 2010;106(2):383-90.

7. Hourton D, Delerive P, Stankova J, Staels B, Chapman MJ, Ninio E. Oxidized low-density lipoprotein and peroxisome-proliferator-activated receptor alpha down-regulate platelet-activatingfactor receptor expression in human macrophages. Biochem J. 2001;354(Pt 1):225-32.

8. Maxfield FR, Tabas I. Role of cholesterol and lipid organization in disease. Nature. 2005;438(7068):612-21.

9. Chang TY, Li BL, Chang CC, Urano Y. Acyl-coenzyme A:cholesterol acyltransferases. Am J Physiol Endocrinol Metab. 2009;297(1):E1-9.

10. Williams KJ, Tabas I. The response-to-retention hypothesis of early atherogenesis. Arterioscler Thromb Vasc Biol. 1995;15(5):551-61.

11. Rigamonti E, Chinetti-Gbaguidi G, Staels B. Regulation of macrophage functions by PPAR-alpha, PPAR-gamma, and LXRs in mice and men. Arterioscler Thromb Vasc Biol. 2008;28(6):1050-9.

12. Viennois E, Mouzat K, Dufour J, Morel L, Lobaccaro JM, Baron S. Selective liver X receptor modulators (SLiMs): what use in human health? Mol Cell Endocrinol. 2012;351(2):129-41.

13. Salehipour M, Javadi E, Reza JZ, Doosti M, Rezaei S, Paknejad M, et al. Polyunsaturated Fatty Acids and Modulation of Cholesterol
Homeostasis in THP-1 Macrophage-Derived Foam Cells. Int J Mol Sci. 2010;11(11):4660-72.

14. Reza JZ, Doosti M, Salehipour M, Packnejad M, Mojarrad M, Heidari M. Modulation peroxisome proliferators activated receptor alpha (PPAR alpha) and acyl coenzyme A: cholesterol acyltransferase1(ACAT1) gene expression by fatty acids in foam cell. Lipids Health Dis. 2009;8:38.

15. Patsouris D, Reddy JK, Muller M, Kersten S. Peroxisome proliferator-activated receptor alpha mediates the effects of high-fat diet on hepatic gene expression. Endocrinology. 2006;147(3):1508-16.

16. van Raalte DH, Li M, Pritchard PH, Wasan KM. Peroxisome proliferator-activated receptor (PPAR)-alpha: a pharmacological target with a promising future. Pharm Res. 2004;21(9):1531-8.

17. Maung K, Miyazaki A, Nomiyama H, Chang CC, Chang TY, Horiuchi S. Induction of acyl-coenzyme A:cholesterol acyltransferase-1 by 1,25-dihydroxyvitamin $\mathrm{D}$ (3) or 9-cis-retinoic acid in undifferentiated THP-1 cells. J Lipid Res. 2001;42(2):181-7.

18. Seo T, Oelkers PM, Giattina MR, Worgall TS, Sturley SL, Deckelbaum RJ. Differential modulation of ACAT1 and ACAT2 transcription and activity by long chain free fatty acids in cultured cells. Biochemistry. 2001;40(15):4756-62.

19. Weldon S, Mitchell S, Kelleher D, Gibney MJ, Roche HM. Conjugated linoleic acid and atherosclerosis: no effect on molecular markers of cholesterol homeostasis in THP-1 macrophages. Ath erosclerosis. 2004;174(2):261-73.

20. Chinetti G, Lestavel S, Fruchart JC, Clavey V, Staels B. Peroxisome proliferator-activated receptor alpha reduces cholesterol esterification in macrophages. Circ Res. 2003;92(2):212-7.

21. Scudiero DA, Shoemaker RH, Paull KD, Monks A, Tierney S, Nofziger TH, et al. Evaluation of a soluble tetrazolium/formazan assay for cell growth and drug sensitivity in culture using human and other tumor cell lines. Cancer Res. 1988;48(17):4827-33.

22. Iida KT, Kawakami Y, Suzuki H, Sone H, Shimano H, Toyoshima $\mathrm{H}$, et al. PPAR gamma ligands, troglitazone and pioglitazone, upregulate expression of HMG-CoA synthase and HMG-CoA reductase gene in THP-1 macrophages. FEBS Lett. 2002;520(1-3):177-81.

23. Bradford MM. A rapid and sensitive method for the quantitation of microgram quantities of protein utilizing the principle of protein-dye binding. Anal Biochem. 1976;72:248-54.

24. Webb NR, Moore KJ. Macrophage-derived foam cells in atherosclerosis: lessons from murine models and implications for therapy. Curr Drug Targets. 2007;8(12):1249-63.

25. Auwerx J. The human leukemia cell line, THP-1: a multifacetted model for the study of monocyte-macrophage differentiation. Experientia.1991;47(1):22-31.

26. Cassol E, Alfano M, Biswas P, Poli G. Monocyte-derived macrophages and myeloid cell lines as targets of HIV-1 replication and persistence. J Leukoc Biol. 2006;80(5):1018-30.

27. Massaro M, Scoditti E, Carluccio MA, De Caterina R. Basic mechanisms behind the effects of n-3 fatty acids on cardiovascular disease. Prostaglandins Leukot Essent Fatty Acids. 2008;79(3-5):109-15.

28. Jung UJ, Torrejon C, Tighe AP, Deckelbaum RJ. n-3 Fatty acids and cardiovascular disease: mechanisms underlying beneficial effects. Am J Clin Nutr. 2008;87(6):2003S-9S.

29. Grundt H, Nilsen DW. n-3 fatty acids and cardiovascular disease. Haematologica. 2008;93(6):807-12.

30. Nakamura YK, Flintoff-Dye N, Omaye ST. Conjugated linoleic acid modulation of risk factors associated with atherosclerosis. Nutr Metab (Lond). 2008;5:22.

31. Munday JS, Thompson KG, James KA. Dietary conjugated linoleic acids promote fatty streak formation in the C57BL/6 mouse atherosclerosis model. BrJ Nutr. 1999;81(3):251-5.

32. McLaren JE, Michael DR, Guschina IA, Harwood JL, Ramji DP. Eicosapentaenoic acid and docosahexaenoic acid regulate modified LDL uptake and macropinocytosis in human macrophages. Lipids. 2011;46(11):1053-61.

33. Zhang J, Kris-Etherton PM, Thompson JT, Hannon DB, Gillies PJ Heuvel JP. Alpha-linolenic acid increases cholesterol efflux in macrophage-derived foam cells by decreasing stearoyl CoA desaturase 1 expression: evidence for a farnesoid-X-receptor mechanism of action. J Nutr Biochem. 2012;23(4):400-9.

34. Chawla A. Control of macrophage activation and function by 
PPARs. Circ Res. 2010;106(10):1559-69.

35. Nagy L, Tontonoz P, Alvarez JG, Chen H, Evans RM. Oxidized LDL regulates macrophage gene expression through ligand activation of PPARgamma. Cell. 1998;93(2):229-40.

36. Sugiyama E, Ishikawa Y, Li Y, Kagai T, Nobayashi M, Tanaka N, et al. Eicosapentaenoic acid lowers plasma and liver cholesterol levels in the presence of peroxisome proliferators-activated receptor alpha. Life Sci. 2008;83(1-2):19-28.

37. Oikari S, Ahtialansaari T, Huotari A, Kiehne K, Folsch UR, Wolffram $S$, et al. Effect of medium- and long-chain fatty acid diets on PPAR and SREBP-1 expression and glucose homeostasis in ACBP-overexpressing transgenic rats. Acta Physiol (Oxf). 2008;194(1):57-65.

38. Coyne GS, Kenny DA, Childs S, Sreenan JM, Waters SM. Dietary $\mathrm{n}-3$ polyunsaturated fatty acids alter the expression of genes involved in prostaglandin biosynthesis in the bovine uterus. Theriogenology. 2008;70(5):772-82.

39. Ruby MA, Goldenson B, Orasanu G, Johnston TP, Plutzky J, Krauss
RM. VLDL hydrolysis by LPL activates PPAR-alpha through generation of unbound fatty acids. J Lipid Res. 2010;51(8):2275-81.

40. Argmann CA, Sawyez CG, McNeil CJ, Hegele RA, Huff MW. Activation of peroxisome proliferator-activated receptor gamma and retinoid X receptor results in net depletion of cellular cholesteryl esters in macrophages exposed to oxidized lipoproteins. Arterioscler Thromb Vasc Biol. 2003;23(3):475-82.

41. Chinetti G, Fruchart JC, Staels B. Transcriptional regulation of macrophage cholesterol trafficking by PPARalpha and LXR. Biochem Soc Trans. 2006;34(Pt 6):1128-31.

42. Wakutsu M, Tsunoda N, Shiba S, Muraki E, Kasono K. Peroxisome proliferator-activated receptors (PPARs)-independent functions of fish oil on glucose and lipid metabolism in diet-induced obese mice. Lipids Health Dis. 2010;9:101.

43. Ecker J, Liebisch G, Patsch W, Schmitz G. The conjugated linoleic acid isomer trans-9,trans-11 is a dietary occurring agonist of liver X receptor alpha. Biochem Biophys Res Commun. 2009;388(4):660-6. 